\title{
Sistemas Agroflorestais: Ressignificação de Vivências em Assentamento Rural Periurbano
}

\author{
Ana Paula Soares da Silva \\ Eda Terezinha de Oliveira Tassara \\ Universidade de São Paulo \\ São Paulo, SP, Brasil
}

\begin{abstract}
RESUMO
O trabalho tem como objetivo investigar como assentados rurais da reforma agrária, na implantação de um sistema agroflorestal, vivenciam novas formas de uso dos bens naturais e como esta vivência provoca ressignificação nos sujeitos e na relação destes com a cidade. Os dados foram construídos por uma abordagem qualitativa, que privilegiou observação participante e entrevistas semiestruturadas realizadas com 5 homens e 2 mulheres, em um assentamento localizado em área periurbana de Ribeirão Preto (SP). Os resultados revelam surpresas relativas à alta produtividade, à diminuição do tempo de trabalho e à economia de recursos hídricos e, consequentemente, a emergência de sujeitos esperançosos na produção, com domínio sobre o tempo e protetores da água. O sistema agroflorestal mediou as tensões com a cidade, oferecendo repertórios e identidades positivas para além das vinculações ao movimento social. Dependente de condições externas, a adesão à prática sustentável se evidenciou como processo em construção.
\end{abstract}

Palavras-chave: Psicologia Ambiental; ambientes rurais; desenvolvimento sustentável; comportamento ecológico.

\section{ABSTRACT}

\section{Agroforestry Systems: Giving a New Meaning to the Peri-Urban Settlements Experiences}

The present work aims at investigating how rural settlers in agrarian reform, while implanting an agroforestry system, experience new uses for natural resources and how this experience brings on new meanings to the subjects and their relationship with the city. Data were collected through a qualitative approach, privileging participant observation and topic guide oriented interviews carried out with 5 men and 2 women in a settlement located in the peri-urban area of Ribeirão Preto (São Paulo). Results show subjects surprised by the high productivity, the decrease in labor time, the economy in hydro resources and, consequently, it also shows the emergence of subjects hopeful on the production, managing over time and practitioners of water conservation. The agroforestry system mediated some strains within the city, offering a repertoire and positive identities that go beyond the bonding to social movements. Dependent on external conditions, the sustainable practice was evidenced as a process in construction.

Keywords: Environmental Psychology; rural environments; sustainable development; ecological behavior.

\section{RESUMEN}

\section{Sistemas Agroflorestales: Resignificación de Vivencias en Asentamiento Rural Periurbano}

El objetivo de este trabajo es investigar cómo asentados rurales de la reforma agraria, en la implantación de un sistema agroflorestal, vivencian nuevas formas de uso de los bienes naturales y cómo esta vivencia provoca resignificación en los sujetos y en la relación de estos con la ciudad. Los datos fueron construidos mediante un abordaje cualitativo, que privilegió observación participante y entrevistas orientadas por la guía de tópicos, realizadas con 5 hombres y 2 mujeres, en un asentamiento localizado en área periurbana de Ribeirão Preto (SP). Los resultados revelaron sorpresas para los asentados relacionadas con la alta productividad, la disminución del tiempo de trabajo y de la economía de recursos hídricos y, consecuentemente, la emergencia de sujetos esperanzados en la producción, con dominio del tiempo y protectores del agua. El sistema agroflorestal medió las tensiones con la ciudad, ofreciendo repertorios e identidades positivas más allá de las vinculaciones al movimiento social. Dependiente de condiciones externas, la adhesión a la práctica sustentable se evidenció como proceso en construcción.

Palabras clave: Psicología Ambiental; ambiente rural; desarrollo sostenible; conducta ecológica. 


\section{INTRODUÇÃO}

Ao longo do século XX, a forte concepção de que a urbanização e a industrialização produziriam a "modernização social" (Froehlich e Monteiro, 2004) resultou na intensificação do domínio técnico-científico sobre a natureza. Como resultado da relação complexa e de interdependência entre o campo e a cidade e da utilização econômica, política e ideológica dos avanços tecnológicos, o mundo rural foi profundamente afetado pela implantação de um modelo de produção agrícola que, iniciado nos anos 50 e consolidado nas décadas de 60 e 70, foi denominado de revolução verde. Sua proposta, justificada pela necessidade de atender às demandas alimentares da sociedade urbana cada vez mais crescente, fundou-se no melhoramento genético de sementes, na mecanização e na agroquímica. Apesar da potencialização da ação humana na produção de alimentos, a exigência do uso extensivo dessas tecnologias gerou grandes impactos do ponto de vista social e ambiental, como o enfraquecimento dos pequenos agricultores e a desvalorização de suas práticas (Alves e Guivant, 2010), o aprofundamento da concentração da propriedade rural, a favelização da população rural nos centros urbanos e a construção de uma relação homem-natureza pautada na degradação dos recursos naturais (Moreira, 2000).

No horizonte do século XXI, caracterizado pela "crise social e ambiental global" (SoromenhoMarques, 2005, p. 11), tanto para o campo como para a cidade, está posto o desafio da construção de alternativas críticas ao modelo dominante de produção e consumo e, consequentemente, ao enfrentamento de seus efeitos. No campo, essa construção tem sido defendida por meio da adoção de princípios agroecológicos, que permitem aliar a conservação dos bens naturais ao fortalecimento da agricultura familiar (Piraux, Silveira, Diniz e Duque, 2012), potencializar os recursos ecossistêmicos do meio natural (Beduschi Filho, 2012) e promover a necessária integração agricultura e sustentabilidade (Alves, Guivant, 2010). As iniciativas recentes de transição agroecológica e de revalorização da natureza caracterizariam um novo rural, denominado por Brandemburg (2010) de rural socioambiental, em convivência e em disputa com os rurais tradicional e moderno.

É nesse contexto que ganha força, na atualidade, a discussão sobre o desenvolvimento rural sustentável, definido não apenas pelos aspectos econômicoprodutivos, mas também relativos à economia agrarioalimentar, ao ambiente natural e, principalmente, à participação das populações que nele residem (CruzSouza, 2011). Essa definição incorpora os elementos econômicos, sociais e culturais que compõem o conceito de desenvolvimento sustentável, institucionalizado pelo Relatório Brundtland, apresentado à conferência das Nações Unidas; conceito esse que, como afirma Pol (2001), embora seja criticável e não consensual entre acadêmicos, políticos e militantes, pode facilitar a criação de um ponto de encontro entre diferentes interesses.

Entre a diversidade de estilos de produção de base ecológica, os chamados Sistemas Agroflorestais SAFs vêm se expandindo nas últimas décadas (Varela e Santana, 2009), também como alternativa para a recuperação de áreas degradadas (Arato, Martins e Ferrari (2003). Do ponto de vista da produção, procurase "imitar o ambiente natural pela consorciação de várias espécies" (Carvalho, Goedert e Armando, 2004, p. 1153). O manejo de espécies arbóreas e agricultáveis ocorre concomitante à preservação ou recuperação da floresta, à promoção da biodiversidade e à produção de renda dos agricultores. Para além de técnicas de manejo, Steenbock, Silva, Froufe e Seoane (2013) afirmam ainda que a prática da agrofloresta é "uma estratégia de reprodução social na qual estão inseridos aspectos econômicos, sociais, culturais e ambientais" (p. 39).

É este entendimento que mais nos interessa desde uma psicologia ambiental orientada para a sustentabilidade (Pol, 2001). Considerando a dinâmica sociocultural dos SAFs, assim como as definições e as iniciativas de desenvolvimento rural sustentável, as relações sociais e as subjetividades deixam de ser "consideradas como externalidades" (Cruz-Souza, 2011, p. 17). Na construção desse rural e na proposição de alternativas produtivas, a psicologia ambiental é provocada a responder, entre outras questões, "que relações emergem da relação agricultores-natureza" (Brandemburg, 2010, p. 424) e como estes se implicam na contestação (ou na submissão) ao modelo hegemônico global de relação ser humano - ambiente natural.

Como afirmam Leite e Dimenstein (2013), diferentemente de outras disciplinas, a psicologia brasileira ainda não conseguiu entrar no debate sobre o meio rural. Alguns importantes trabalhos são pontuais e a produção de grupos consolidados nessa temática está em processo de construção

Essa realidade não é diversa de outros países e nem mesmo na psicologia ambiental. Moser (2009) afirma que o ambiente rural é pouco investigado na área, com exceção para estudos sobre a relação dos agricultores com a natureza. $\mathrm{O}$ autor, a partir de pesquisas no rural europeu, defende que os agricultores possuem uma relação ambígua com a natureza, uma vez que dependem dos usos de recursos necessários para a satisfação 
de suas necessidades e, ao mesmo tempo, precisam lidar com a degradação que essa utilização acarreta. Atuam assim, nos comportamentos sustentáveis, elementos culturais que conjugam as imagens sociais do papel dos agricultores na preservação ou degradação da natureza e, principalmente, elementos profissionais, vinculados aos recursos e ao sentimento de eficácia e de controle dos agricultores. As incertezas profissionais, ambientais e sociais interagem e produzem diferentes tipos particulares de relação com o ambiente. O sentimento de responsabilidade e de implicação pessoal na melhoria do ambiente e uma concepção ideológica de natureza como vulnerável apareceriam somente no caso dos agricultores orgânicos.

Ryan, Erickson e De Young (2003), no estudo do envolvimento de agricultores estadunidenses em práticas de conservação e preservação ambiental em áreas ripárias, percorrem a tese já explorada em seus estudos anteriores de que as motivações extrínsecas, como recursos financeiros ou subsídios governamentais, não seriam os principais fatores nesse processo. Os fatores intrínsecos, como o apego à terra e a sua proteção para as gerações futuras, apoiariam de modo mais consistente e duradouro as decisões de engajamento em práticas sustentáveis.

No debate sobre a produção agroecológica como alternativa ao modelo hegemônico de agricultura e sobre a construção do novo rural socioambiental, propomos compreender a experiência de agricultores rurais da reforma agrária em práticas sustentáveis, recuperando e problematizando os conceitos de esperança projetual de Maldonado (1971) e de periurbanidade, elaborado por Tassara (2007).

O conceito de esperança projetual (Maldonado, 1971) expandiu-se de sua área original como contribuição a várias disciplinas que operam com a construção intencional do presente e do futuro, ou seja, com a política, a gestão e a educação ambientais. $\mathrm{O}$ conceito foi desenvolvido na proposição de uma "teoria geral da práxis projetual” (p. 128), que busca compreender a "consciência operante do homem sobre seu entorno físico e sociocultural" (p. 23), sem desconectá-la da esperança nela presente (p. 32). Para Maldonado, o ser humano e sua práxis adquirem centralidade nas determinações da condição e do entorno humanos. Natureza e sociedade são concebidos num mesmo horizonte problemático que, para além dos argumentos ecológicos produzidos como parte de modismo de época, precisa ser enfrentado por uma utopia orientada por projetos, ou seja, a "esperança projetual” (Madonado, 1971, p. 146). Ferraro Júnior e Sorrentino (2011) utilizam o conceito de esperança projetual na análise das políticas brasileiras de educação ambiental.
Por sua vez, o conceito de periurbanidade, proposto por Tassara (2007), foi elaborado para compreender situações cuja relação de constituição dos sujeitos é de contra-hegemonia e foi definido enquanto um movimento e uma dinâmica de produção crítica ao modelo de urbanidade. Periurbanos "seriam os tipos de modelos (dos quais os seres humanos seriam substrato) que giram, que gravitam em torno de uma representação hegemônica da urbanidade ou que dela se distinguem, emergindo das diferenças culturais" (2007, p. 17). Nesse contexto, pode-se dizer de um processo de construção de identidades periurbanas, posicionadas e construídas entre as forças homogeneizadoras e aquelas possibilitadas pela diversidade local, material ou simbólica.

Com base nesses conceitos e a partir da retórica presente na literatura acerca da produção agrícola orientada por práticas agroflorestais, quando se coloca em relevo o envolvimento dos sujeitos nessas práticas, pode-se supor que haja, a priori: (i) um "caráter de aspiração a mudanças dos sujeitos sociais sobre a relação sujeito-ambiente" (Tassara e Rabinovich, 2003, p. 340); (ii) a construção de uma "consciência ecológica essencialmente crítica", orientada por projetos investidos de esperança (Madonado, 1971, p. 146). A crítica e a esperança, presentes nas propostas de produção por meio de SAF, teriam suas marcas impressas nos sujeitos.

No aprofundamento e na problematização a esses conceitos, recorremos a uma experiência inicial de implantação de um sistema agroflorestal no contexto de um assentamento rural da reforma agrária. Os assentamentos rurais da reforma agrária consistem na efetivação de política pública prevista pela Constituição de 1988, como instrumento de reorganização da estrutura fundiária e de garantia da função social da terra, em seus requisitos econômico, ambiental e social. Considerando as relações norte-sul, os assentamentos brasileiros da reforma agrária caracterizam-se como um rural bastante particular, diferente daqueles investigados por pesquisadores nos países do norte, o que pode indicar também processos diferenciados. Abordar os assentamentos rurais da reforma agrária desde uma mirada com foco na questão ambiental permite confrontar as dinâmicas mobilizadoras de periurbanidades e de esperança projetual, supostamente presentes nas práticas sustentáveis, com a complexidade dessa realidade no contexto brasileiro. A inserção dos assentados em projetos da reforma agrária ocorre por motivos inicialmente bastante distantes de um ideário ecológico, vez que está relacionada diretamente com a luta pela própria sobrevivência imediata, com a criação de alternativas para o enfrenta- 
mento à pobreza e com o desejo de obtenção da terra. Também a incorporação dos princípios da agroecologia, nos movimentos pela reforma agrária, é recente. Por exemplo, o Movimento dos Trabalhadores Rurais Sem Terra - MST, o maior movimento social de luta pela terra no Brasil, ocorreu em meados da década de 90 e, apesar de grandes avanços no nível discursivo, busca seu caminho no sentido de sua consolidação nas práticas cotidianas (Silva, 2011). A aproximação entre o assentado e o modelo de produção proporcionada pelo SAF é, portanto, uma construção

Defende-se que acompanhar essa construção pode evidenciar elementos que, antes de serem motivações intrínsecas ou a priori para o engajamento em práticas sustentáveis, são produtos da própria atividade dos sujeitos no espaço a que se propõem construir. Essa evidenciação colabora para o entendimento dialético da relação entre o que Pol (2009) denomina de determinantes internos e externos do comportamento sustentável. Para o autor, a literatura "majoritariamente está centrada em 'determinantes internos' (valores, atitude, etc.) e em menor medida em 'determinantes externos' (recursos e oportunidades para o comportamento desejado, influência social, etc.)" (p. 186). Se o interesse está na unidade sujeito-meio, é necessário compreender as vivências dos sujeitos nas práticas sustentáveis e, ao mesmo tempo, as modificações que elas também produzem nos sujeitos.

Investigar o desenvolvimento da relação do sujeito com o espaço reconstruído por suas próprias mãos, como é o caso dos SAFs e da implantação de projetos agroecológicos em assentamentos rurais, é também enriquecer as formas de compreender os sujeitos nesse e desse espaço, uma vez que, geralmente, são investigados pela filiação aos movimentos sociais e seus processos de participação política. Mas é, principalmente, colocar como relevo, nas múltiplas determinações da constituição dos sujeitos, a relação pessoa - ambiente, sem desconsiderar a complexidade social, cultural, política, ética e econômica dessa relação.

\section{OBJETIVOS}

O trabalho tem como objetivo investigar como assentados rurais da reforma agrária, em processo inicial de implantação de um sistema agroflorestal, vivenciam a emergência de novas formas de uso dos bens naturais e como esta vivência provoca ressignificações nos próprios sujeitos e na relação destes com a cidade.

\section{MÉTODO}

\section{$O$ contexto da pesquisa: características socioambientais do assentamento}

O assentamento rural pesquisado, denominado Mário Lago, localiza-se nos limites da periferia urbana da cidade de Ribeirão Preto, Estado de São Paulo. Originalmente, era uma antiga fazenda de monocultura da cana-de-açúcar, com pouquíssimas áreas remanescentes de floresta. A iniciativa do pedido de desapropriação da área para fins de reforma agrária aconteceu em 2000, pela Promotoria de Justiça do Meio Ambiente e Conflitos Agrários que requisitou ao Instituto Nacional de Colonização e Reforma Agrária - INCRA a desapropriação, devido elevado passivo ambiental e suspeita de improdutividade econômica. Em 2003, o MST ocupou a antiga fazenda e passou a conviver com reiteradas reintegrações de posse até que a fazenda fosse desapropriada por decreto presidencial, em 2005. O assentamento representou uma concepção vitoriosa em direção ao rural, no embate que se travou na franja urbana em que se localiza. A área vivia um conflito ambiental e era, ao mesmo tempo, objeto de disputa de projetos diferentes de ocupação: rural, mantido pelos assentados e movimentos sociais ambientalistas e ligados à reforma agrária; urbana, representado pelos interesses de empresários do setor imobiliário em lotear a fazenda e transformá-la em área de expansão.

No período de 2005 a 2011, após discussões coletivas conduzidas pelo Ministério Público e com a presença de assentados e representantes da sociedade civil, é adotado o modelo dos SAFs. O INCRA e os assentados assinam um termo de ajustamento de conduta comprometendo-se com a implantação do SAF. Dois desafios foram assumidos: o da viabilização da produção e o da recuperação ambiental da área. A organização espacial do assentamento foi planejada por meio de áreas de produção coletiva (de forma cooperada), pequenas áreas de produção familiar e áreas de uso comum para atividades sociais, culturais e de lazer (Firmiano, 2008). O assentamento está situado sobre uma das áreas de recarga do Aquífero Guarani, o que fez com que os limites de proteção de reserva legal também fossem ampliados; as águas subterrâneas deste aquífero distribuem-se por oito Estados brasileiros e pelo Paraguai, Argentina e Uruguai.

Em 2013, o assentamento abrigava 550 famílias, 260 delas vinculadas ao MST. Na área vinculada ao MST, havia duas cooperativas envolvidas na implantação do SAF em sete áreas coletivas. Uma das cooperativas possuía aproximadamente 30 famílias e a outra, em torno de 90. As demais famílias ainda 
não tinham se engajado na produção coletiva nas áreas de SAF. Na implantação do SAF, decisiva foi a colaboração recebida pela organização Coopera Floresta, Associação dos Agricultores Agroflorestais de Barra do Turvo/SP e Adrianópolis/PR, por meio do Projeto Agroflorestar: Co-operando com a Natureza. Essa Associação tem experiência com SAFs desde a década de 90 e presta assessoria técnica ao assentamento Mário Lago desde meados de 2012.

\section{Participantes}

Sete adultos foram informantes privilegiados nesta pesquisa: Mestre, Valter, Dinho, Jeziel, Rosa, Samara e Saul ${ }^{1}$. Suas idades variavam entre 20 e 50 anos. Eles faziam ou fizeram parte da coordenação do assentamento ou de setores de educação e de produção. Dois deles cursaram graduação, um deles realizava um curso de técnico em agroecologia (oferecido pelo próprio MST) e os outros três tinham formação no ensino médio ou fundamental incompleto. Três deles possuíam em suas histórias de vida experiência direta de trabalho com a terra e os outros eram filhos de agricultores ou ex-agricultores. Todos moravam em periferia urbana antes da inserção no movimento social e no assentamento Mário Lago.

\section{Instrumentos e procedimentos de coleta}

Os dados da pesquisa foram construídos por uma abordagem qualitativa, derivados da inserção da pesquisadora no assentamento, em atividades de extensão, desde 2007.

Registros de participação em reuniões, assembleias de discussão sobre o modelo do assentamento e atividades culturais compuseram informações em notas de campo que permitiram recuperar aspectos da história da relação dos assentados com o SAF. A inserção e o registro orientaram-se pelos princípios da pesquisa direta ou também chamada observação participante (Jacoud e Mayer, 2008).

Em maio de 2013, foi composto também um conjunto de informações a partir de entrevistas orientadas por um tópico guia (Gaskell, 2013). A entrevista é entendia como um artefato científico na relação entre os participantes - pesquisador e informantes -, o que a configura como uma interação particular em função dos papéis de cada um desses sujeitos (Silva, 2003). Os informantes privilegiados foram sete adultos. As entrevistas variaram de uma a três horas e ocorreram nas próprias áreas de $\mathrm{SAF}$, o que tornou possível

\footnotetext{
Os nomes são fictícios, sendo que os de Samara e Saul, que são marido e mulher, foram escolhidos pelos próprios participantes. O projeto foi aprovado pelo Comitê de Ética em Pesquisa com Seres Humanos do Instituto de Psicologia - IPUSP.
}

caminhar pelo assentamento, conhecer a produção, conversar com outros assentados que transitavam nas áreas coletivas, durante as entrevistas. Os tópicos que guiaram a conversa com os participantes foram: a metodologia utilizada para a implantação do SAF; as avaliações acerca do SAF em comparação com outros modelos; os benefícios e as dificuldades na sua implantação; o envolvimento pessoal e coletivo com o projeto do SAF; o envolvimento das gerações futuras; as relações com a cidade e com o entorno do assentamento. Ao final da entrevista ou ao longo de seu desenvolvimento, a depender de seu fluxo, perguntava-se ao (a) participante: se ele(a) se considerava rural ou urbano, e se ele(a) conseguia imaginar o assentamento no futuro. Por fim, solicitava-se que o(a) participante indicasse os lugares para ele(a) mais significativos no assentamento, seguido de uma justificativa sobre esta escolha. No caso de lugares próximos, uma máquina fotográfica era disponibilizada ao participante para o registro das imagens indicadas. Nesse artigo, da entrevista, privilegiamos a análise do material derivado do tópico guia sobre a experiência com o SAF.

\section{Tratamento do material e análise}

As entrevistas foram transcritas e leituras realizadas para a construção das categorias de análise. As palavras dos sujeitos, produzidas na situação interativa da entrevista, foram tratadas como carregadas de significados e sentidos acerca de suas experiências no SAF, ou seja, como significações das vivências partilhadas e espacialmente localizadas dos participantes. Esse tratamento fundamenta-se na perspectiva vigotskiana, que admite a centralidade dos processos de significação na constituição dos sujeitos e no compartilhamento da experiência humana acumulada e singularizada em grupos culturais. Para Vygotski (2006), a vivência, inclusive aquela atribuída de sentido, é a unidade para o estudo da relação meio e pessoa. A vivência possui para ao autor uma “orientação biossocial, é algo intermediário entre a personalidade e o meio" (p. 383). Nesse sentido, é o modo como se vivencia uma determinada situação e, portanto, a forma como ela é significada, que nos revela sobre o meio e as relações da pessoa com as diversas facetas deste meio.

Foram identificadas, no material, as significações dos participantes sobre as vivências na implantação do SAF. Nesse tratamento, especial atenção foi dada àquelas situações que indicavam processos de ressignificação das vivências, o que poderia evidenciar instantes de novas relações socioespaciais e, consequentemente, mudanças nos processos de produção de sujeitos encarnados no espaço. Essas ressignificações, orientadas pelos conceitos de 
esperança projetual e de periurbanidade, foram tratadas em dois grandes blocos: a esperança depositada no SAF e o SAF na mediação com a cidade. No primeiro bloco, três elementos de ressignificação apareceram no material com maior força, a partir do relato da vivência com o SAF, constituindo-se eixos de análise: a dimensão econômica, relativa às significações sobre o tamanho do lote e sua consequente viabilidade produtiva; a dimensão ecológica, com destaque para significações sobre a importância de preservação dos recursos hídricos; a dimensão temporal, relativa ao esforço e ao tempo gastos na produção agroflorestal. No segundo bloco, buscou-se compreender possíveis transformações das relações dos sujeitos com a cidade e as mediações exercidas pelo SAF nesse processo, inclusive na oferta de repertórios que ampliam a identificação dos assentados para além de suas filiações mais visíveis. No conjunto do material, supunha-se que estas novas significações e relações com o espaço do assentamento poderiam compor novos quadros de vivência e, portanto, também novos sujeitos. Daí que em cada um dos itens buscou-se abstrair que sujeito emergia nos momentos de relato daquela vivência. Por último, as informações registradas em notas de campo colaboraram na recuperação de dados relativos ao processo de envolvimento dos assentados e na narrativa interpretativa dos resultados obtidos nas entrevistas.

\section{RESULTADOS}

\section{A esperança depositada no SAF}

Embora o projeto agroflorestal fosse objeto de discussão desde o início do assentamento, as condições para sua concretização variaram bastante, dependentes que estiveram da estruturação mínima da localidade: organização espacial dos lotes e das áreas coletivas, distribuição de energia elétrica e de água e financiamento para construção das moradias. Até o começo efetivo do SAF, em 2012, intercalaram-se iniciativas pontuais nos lotes individuais, mais ou menos orientadas por princípios agroecológicos. Essas iniciativas concorreram com o tempo gasto na militância por melhores condições no assentamento, na organização socioespacial e em trabalhos na cidade para garantir alguma renda enquanto os financiamentos públicos não se consumavam. Também iniciativas de monocultura foram construídas pelos assentados, nesse caso, principalmente nos lotes individuais. A ausência de recursos técnicos, financeiros e formativos foi elemento importante nos movimentos de aproximação e distanciamento da construção do SAF, colaborando para a adesão ou não dos assentados às cooperativas. É somente com a chegada do Projeto Agroflorestar e com as atividades de produção nas áreas coletivas que a esperança depositada no modelo de assentamento agroflorestal renova-se.

\section{Da dimensão econômica}

O tamanho dos lotes individuais no Mário Lago, comparado a outros assentamentos, era significado como bastante pequeno, resultado do excessivo aumento no número de acampados ao longo do demorado processo de regularização da área para a reforma agrária. Esse motivo gerou, tanto nos assentados como nos técnicos, dúvidas em relação à viabilidade econômica e à capacidade de geração de renda do assentamento. Essa dúvida constantemente esteve presente na discussão acerca dos investimentos públicos e pessoais, colaborando como ingrediente de tensão nas expectativas que se criaram, na cidade e na região, acerca do futuro e do sucesso da reforma agrária naquela área.

A surpresa e a possibilidade de viabilizar a sobrevivência no assentamento emergiram, para os assentados, quando eles começaram o processo de produção coletiva nas áreas de SAF. Todos mencionaram enfaticamente a ressignificação em relação a esta questão:

Mestre: Tem pessoas que questionam o tamanho do lote. Eu discordo plenamente disto. Se você trabalhar nele de uma maneira correta, voltada para a vida, para o sustentável... olha, você não dá conta da produção!

Valter: Mas o principal é que você consegue produzir muito numa área de terra muito pequena.

Rosa: É claro, ninguém gostou de ter 1,5 hectare. Só que a gente agora está conseguindo perceber que 1,5 hectare é muuito. Por causa que é muito produtivo.

Ana Paula: Vocês estão sentindo isso?

Rosa: Não! O Povo está sentindo! A gente fez uma roda de conversa, do núcleo, faz uns 15 dias, que era sobre esse assunto. O tema era projeto ambiental. Aí a gente foi conversando. Nossa! Cada depoimento! Um senhor disse: "Eu deixei meu lote um pouco de lado, eu estou só na área coletiva do SAF. Por quê? Porque eu estou vendo que no SAF é que está dando a minha renda, e ainda eu estou aprendendo!” (...) E meu Deus, como é que dá tanta produção?! E dá muuuito, numa quantidade de terra pequena.

A avaliação positiva desta experiência, potencializada pela comparação com tentativas fracassadas de produção pelo método convencional, constitui-se 
mobilizadora para a continuidade de sua implantação. São vários os relatos dos assentados ressaltando o sucesso do SAF em relação aos prejuízos que tiveram na preparação da terra, no combate de pragas, na comercialização dos produtos e na renda ao final do processo quando experimentaram o modelo baseado na cultura de um único produto. De sujeitos fracassados e sem perspectiva de efetivação do sonho da reforma agrária na terra conquistada, nesse processo, produzse um sujeito-esperança-na-produção que, para a execução do projeto, mobiliza recursos e tempos na agenda das atividades fora do assentamento e de militância.

\section{Da dimensão ecológica}

Outro processo de ressignificação se verifica em relação à quantidade de água necessária para a produção e, consequentemente, a derivação ecológica dessa questão. A água é a própria fonte da conquista daquela terra e a justificativa para o pedido de desapropriação da área baseada em argumentos ambientais. Ao mesmo tempo, e principalmente por isto, é ela fonte de desafios, uma vez que o estar naquele lugar é dimensionado pelo fato dos assentados terem, sob os próprios pés, uma área de recarga do Aquífero Guarani. Os entraves na captação e distribuição da água, gerados pela preocupação com o Aquífero e pela falta de incentivos governamentais, fizeram da relação com a água a questão central durante longo período no assentamento e sua resolução era tida como crucial para a concretização do assentamento enquanto um espaço de produção agrícola. Todos os assentados entrevistados mencionaram os impactos visíveis nessa problemática a partir da vivência com o SAF.

Rosa: Outra coisa é o negócio da água. Enfim, como resolver este problema de água, de irrigação? E a gente começou a se dar conta disto. Porque, se o solo está alimentado, a quantidade de água é muito menor. E a nossa ideia é sempre essa... É claro, é muito importante fazer barramento, ter água de irrigação, lutar com o INCRA para resolver isso, e tal... Só que, pesando na questão até de ser minimamente sustentável, você pensar num negócio que se quer mais água sem tentar alimentar a terra, é também um equívoco. Pensa-se em mais recurso, mas não se pensa em como aproveitar o que já existe. Então essas duas coisas, foram uma cacetada para nós: a quantidade de terra e a água. Isso deu muito nó na nossa cabeça.

Muitos assentados não iniciaram seu processo de produção justificando a ausência de um vigoroso sistema de captação e distribuição da água. As técnicas de plantio do SAF minimizam ao máximo o uso da água, pelo aproveitamento de matéria orgânica, pela proteção do solo e pelo sombreamento que as espécies consorciadas promovem. A experiência concreta evidenciou que a quantidade de água suficiente para o plantio é bem menor do que a imaginada pelos assentados. Para além da surpresa acerca da menor quantidade, uma vez que não se quer negar que a água é importante para a produção, o que se verifica é a forte vinculação deste pensamento com os ideais ambientais que estão postos no horizonte dos assentados. A economia do recurso hídrico fortalece enormemente o sentimento de responsabilidade ambiental dos assentados. Em articulação com um sujeitoesperança-na-produção, constrói-se o sujeito-protetordo-ambiente.

Esta imagem de protetor do ambiente aparece em várias falas, o que serve de indícios para explorar as transformações dos sujeitos promovidas pela participação em um assentamento agroflorestal, independentemente de estarem ou não envolvidos diretamente com a implantação das áreas de SAF.

Samara: Quando eu converso [com as pessoas de fora], eu assim: que esta fazenda estava nas mãos de uma pessoa só e hoje está dividida onde as pessoas podem ter um lugar para morar, um lugar para produzir e também pode reflorestar. E o cuidado também destas pessoas, a responsabilidade, o compromisso com Ribeirão, com a população de Ribeirão. E proteger o Aquífero Guarani, ter cuidado para não contaminar o Aquífero e não ter também transgênicos. (...) Para as pessoas entenderem que a gente não quer só para gente, a gente pensa lá fora, está pensando na cidade, que alimentos vai oferecer. (...) O Aquífero, o lençol abastece toda Ribeirão Preto. O assentado contribui nessa parte. Preocupa com a saúde, com a vida das pessoas que moram lá fora. Que nossa luta não é só para as pessoas que moram aqui, mas em geral, todos que precisam e que dependem dessa água. Também o reflorestamento. Se o Aquífero for esvaziando, daí a pouco vai ter falta de água. Com o reflorestamento, pode ter mais água.

Samara e Saul, embora possuam sua área de SAF reservada e tenham feito o plantio de apenas algumas mudas, ancoram nas atividades fora do assentamento a garantia da renda e o uso principal do tempo diário. Participar de um processo mais amplo, contudo, é elemento fundamental na definição de si mesmo, em relação a um bem natural e em relação ao conjunto da 
população. Mestre destaca, nessa mesma direção, certo orgulho em colaborar para a "recuperação e produção de diversas formas de vida" naquela localidade. Observa-se o que podemos denominar de expansão do sujeito no mundo, cujas ações repercutem extrapolando os limites do assentamento, ao mesmo tempo em que os implica como sujeitos responsáveis pelo solo particular que ocupam. Mais ainda, verifica-se a construção de um sentimento de integração orgânica, como parte importante daquele ambiente.

\section{Da dimensão temporal}

O terceiro aspecto que se modifica na vivência do SAF refere-se ao significado sobre o esforço e o tempo gastos no trabalho agrícola.

Valter: Uma das coisas que a gente mais se identificou aqui é pensando na mão-de-obra. Por exemplo, você não precisa se matar na enxada. Esse negócio de queimar, trabalhar, e limpar, limpar, limpar, e depois roçar, cuidar, colher... Acabou. (...) $\mathrm{O}$ que você vai fazer é manejo; tirar o excesso de material orgânico e trazer para a linha do plantio do SAF. (...) A produção que dá de verdura é muito grande, sem aguar, sem fazer quase nada. (...) Porque você não precisa ficar capinando. Se você colocar bastante cobertura não tem mato, não tem carrapicho... só manejando no facão.

Dinho: Até meu pai, que plantava milho [como cultura única], quando viu, falou: "Nossa, eu acho que estou trabalhando demais".

O trabalho na agricultura é árduo e, portanto, melhores condições e esforços de mão-de-obra reduzidos na produção são significados como um grande diferencial em relação ao sistema de cultivo baseado em técnicas modernas. Trabalho em áreas sombreadas, não utilização de agrotóxico, uso de instrumentos de trabalho simplificados e atividades menos penosas compõem um quadro que permite, aos assentados, conciliar o tempo gasto no SAF com outras atividades. Todos relatam que o investimento no SAF demanda, por dia, de duas a três horas, possibilitando a conciliação do cultivo nas áreas coletivas com outras atividades nos lotes individuais ou fora do assentamento. Nesta produção, surge um sujeito-quemaneja-o-tempo.

Cabe dizer que o próprio processo do SAF é ele mesmo, resultado de planejamentos temporais sucessivos.

Valter: O bom do SAF é que você consegue planejar a vida. No final do ano, por exemplo, eu quero uma renda para passar o Natal mais sossegado, fazer uma viagem. Então você vai plantar ali pensando no final do ano. Daqui 5 anos eu quero trocar de carro. Então você planta ali pensando em colher. Daqui 60 anos eu vou aposentar. Então você planta ali pensando o que 60 anos você vai colher. Tipo o mogno, essa arvorezinha aqui. Ela fica boa para corte daqui 30 anos. Eu quero aposentar, então você planta 200 árvores de mogno aqui e você vai ter uma aposentadoria para você.

No planejamento das atividades de plantio e colheita, o tempo se interpõe em escalas diversas, uma vez que o assentado necessita coordenar o consórcio de culturas variadas a permitir tanto o retorno econômico imediato como o investimento em espécies cujo retorno financeiro ocorrerá a muito longo prazo. Nas áreas em que a floresta ainda não foi reconstruída, é necessário muito planejamento, realizado por meio do conhecimento da flora nativa e de culturas agrícolas. Esses diferentes tempos exigem dos assentados um exercício intenso de projeção e planejamento em escalas temporais diversas, complexificando a relação entre o presente e o futuro.

A dimensão temporal atua ainda como uma importante força nos movimentos de adesão ou não ao SAF entre os assentados. Como já dito, a vivência nas áreas de SAF é diferenciada para o conjunto dos assentados e também para os participantes da pesquisa. Saul e Samara, que trabalham predominantemente fora do assentamento, fizeram apenas aproximações à área coletiva e com ela mantinham pouca relação. Os demais participantes, por sua vez, demonstram investimentos de tempo ampliados. O tempo, como resultado de economia de trabalho proporcionada pelo SAF ou transformado em trabalho fora do assentamento, articula-se necessariamente com as possibilidades de se depositar esperanças na viabilidade do assentamento agroflorestal. As atividades no SAF ou fora do assentamento relacionavam-se assim, em determinado sentido, como forças complementares e, em outro, como forças concorrentes. Como as condições para a implantação do SAF ainda não estavam plenamente dadas, os assentados buscavam complementar a renda fora do assentamento, principalmente como trabalhadores na construção civil, no caso dos homens, e como empregadas domésticas no caso das mulheres. Concomitantemente, a busca para viabilizar a sobrevivência concorria com o próprio projeto coletivo de reflorestamento e geração de renda por este sistema. Enfim, lidar com o tempo compunha o conjunto de tensões no processo de implantação dessa proposta. 


\section{O SAF na mediação com a cidade}

A vivência da relação com a cidade é também permeada pelas transformações nas concepções acerca dos assentados.

Ana Paula: E como é a relação com o entorno, com o bairro, com a cidade?

Mestre: É uma coisa que você tem muita dificuldade. Agora melhorou muito. Antes a coisa era muito pior. Então a gente vai relacionando isso porque a sociedade tem uma visão do MST que é o que a mídia mostra. (...) O que é isto? Falta de conhecer. Então assim, com os exemplos que a gente vem mostrando, com o trabalho da educação. Quer dizer assim, vai depender muito do trabalho. E no campo da produção não vai ser diferente.

Ana Paula: E por que melhorou?

Mestre: Porque as pessoas vão nos conhecendo e vão entendendo que não é isto. Somos pessoas... Somos da sociedade. (...) Mostrar pra sociedade que existe outra maneira de produzir, não é só isso que está aí.

O relato de Mestre exemplifica o que apareceu em várias situações testemunhadas pela pesquisadora durante toda a inserção prolongada no assentamento. Relatos de preconceito na escola pelas crianças e de situações de humilhação no comércio foram freqüentes quando da chegada dos assentados naquela área e nos anos iniciais de implantação do assentamento. Contudo, com o SAF, a oferta de produtos saudáveis e o início da recuperação da mata constituíram-se em poderosos argumentos na retórica sobre os assentados, seja produzida por eles mesmos, seja pelo outro, representado pelos moradores da cidade em seus discursos. Mestre conta que enfrentou dificuldades, durante um ano, na venda dos produtos na cidade. Como parte de uma ação coordenada com a associação de moradores de um bairro da cidade, todos os domingos, passou a comercializar os produtos da sua cooperativa. Um dos vizinhos, incomodado com a presença dos assentados e com a vinculação com o MST, fez várias investidas contrárias àquela presença e chegou inclusive a acionar algumas vezes a polícia. Com perseverança, o assentado viu, naquela atitude hostil, um desafio orientado para a necessidade de convencimento sobre o projeto do assentamento. E não desistiu do diálogo com esse morador. Fala com alegria que aquele homem "tornou-se um comprador dos nossos produtos".

Em relação à ressignificação de si mesmo, o caso do Mestre evidencia que a participação no SAF criou possibilidades de apresentar-se ao outro como um sujeito com outras facetas, além de membro de um movimento social ou circunscrito às possibilidades de identificação dadas pelo binômico rural-urbano, ou seja, camponês ou citadino. Constrói-se um sujeitoprodutor-sustentável:

Mestre: Eu já me considero como um pequeno produtor sustentável. E já me considero, eu já tenho uma visão de um pequeno produtor já sustentável. (...) O sustentável, que eu imagino, é onde eu já consigo tirar meu próprio sustento da terra e estou contribuindo com a vida. Por exemplo, eu tenho certeza que eu estou contribuindo com o Aquífero Guarani, eu tenho certeza que eu estou contribuindo com outro jeito de vida.

Ana Paula: E o que é a vida?

Mestre: A vida, às vezes a gente fala a vida é só eu estar vivendo. Acho que não, a vida é todo um sistema, um ecossistema, uma questão produtiva em volta. Por exemplo, há dez anos, você não via aqui pequenos animais. Botava cana aqui e não existia. Hoje você anda aí no meio desse colonhão você vê tanto pequenos animais e acho que isso faz parte da biodiversidade, da natureza. Eu me considero muito um pequeno produtor sustentável nesse sentido.

O SAF exerce um papel mediador com o entorno e na ampliação de repertórios positivos de si no contato com outros. Para Valter, a mediação da relação com a cidade se faz pela divulgação do que é o SAF. Relata a visita de muitas pessoas ao assentamento, na busca de compreensão de como o assentamento se organiza e de como produz:

Valter: Aonde a produção entra mostrando essa cara do assentamento muda muito as pessoas em relação ao que pensam do assentamento. É uma preocupação nossa, que temos assim esse entendimento. Não é só ficar lá na feira vendendo os produtos. Tem que entender um pouco essa lógica.

O convencimento do projeto acontece pela necessária disseminação do modelo, mas principalmente, de sua viabilidade. Em outras palavras, é preciso criar o seu sucesso para fortalecer a própria escolha e para ganhar novos sujeitos na adesão ao modelo e, consequentemente, na transformação das significações negativas que possuem sobre os assentados. A apresentação do modelo à sociedade é parte importante na disputa cultural pela aceitação 
social dos assentados, do movimento social e da existência daquele assentamento na região. Nesse esforço, os assentados manifestam-se ativamente na construção de uma periurbanidade. Apresentam-se enquanto sujeitos que possuem uma lógica diferenciada daquela dominante na cidade e com um projeto contrahegemônico de produção agrícola, de relação com a natureza e de relação produtor-consumidor. Apoiam-se na afirmação positiva de si, no amplo alcance de seus atos e na produção de vida que promovem no lugar.

\section{CONSIDERAÇÕES FINAIS}

O acompanhamento da participação de assentados rurais na implantação de um SAF evidencia um processo de ressignificação das possibilidades de relação econômica, temporal e ambiental com o lugar que eles ocupam. Esse processo faz parte do movimento de aproximação ou distanciamento dos assentados na adoção da prática agroflorestal. Posicionados entre as dificuldades financeiras e técnicas de execução do projeto e ações individuais de produção baseadas na monocultura, os assentados transitavam entre a esperança e a descrença de fazer, do assentamento, uma fonte de renda; conseqüentemente, de sucesso ou não do projeto de reforma agrária para o local e de enfretamento de suas condições de pobreza. Das várias tentativas fracassadas, a esperança na possibilidade de construção de um presente e de um futuro viáveis economicamente e sustentáveis do ponto de vista ambiental, projetada em assembleias e reuniões, renovase com a chegada de recursos e de assessoria técnica promovida pela cooperativa já experiente em SAFs. São o engajamento na produção coletiva, o exercício de planejamento do plantio e de comercialização dos produtos, o confronto com a alta produtividade no espaço reduzido e em condições de limitado uso da água que provocaram efeitos transformadores em suas práticas e significações e, conseqüentemente, em si mesmos enquanto sujeitos daquele espaço. É possível, nesse processo, identificar instantes em que emergem sujeitos esperançosos na produção, sujeitos com maior domínio sobre o tempo, sujeitos promotores e protetores da vida.

As vivências no assentamento, contudo, não são homogêneas e, no relato dos assentados, como fundo, aparecem como interlocutores outros assentados, ainda não engajados na implantação do SAF ou convencidos de sua potencialidade na efetivação de um projeto que dê conta de recuperar o ambiente natural e, ao mesmo tempo, gerar renda. Estas tensões dialogam com, são produzidas por e influenciam $a$ esperança projectual (Maldonado, 1971) depositada pelos assentados no
SAF. De mesmo modo, as subjetividades emergentes são tensionadas nesse diálogo, podendo ser fortalecidas ou não na condição de periurbanidade (Tassara, 2007) que o projeto porta. Tanto a esperança projetual como a condição de periurbanidade (Tassara, 2007) são condições constituintes da mobilização de significações acerca da relação ser humano-ambiente natural, assim como de transformações dos sujeitos. Entretanto, ao mesmo tempo, fica evidente que a ausência de condições plenas para a efetivação do projeto potencializa tensões e fragiliza as novas significações e os novos sujeitos.

Esses resultados apontam para uma necessária incorporação da noção de processo nos conceitos de esperança projetual e de periurbanidade. A crítica ao modelo hegemônico de produção agrícola e a esperança no novo modelo se mostram componentes dinâmicos do processo de adesão ao SAF, dependentes de uma série de elementos que se interrelacionam. Não são, portanto, processos acabados. Ao mesmo tempo, esses resultados dialogam com os estudos de Ryan, Erickson e De Young (2003) e de Moser (2009). A dinâmica verificada no processo inicial de implantação de um SAF demonstra que é difícil separar as motivações internas e externas do processo de engajamento dos assentados na prática agroflorestal. Diferentemente do que aponta o estudo com os agricultores estadunidenses, no contexto de assentamento da reforma agrária, a rede de oportunidades financeiras, técnicas e formativas, disponibilizada por uma cooperativa já experiente em agrofloresta, foi fundamental para criar condições de sucesso e de atividades significativas aos assentados. Fica evidente que o engajamento em práticas sustentáveis, muito menos do que uma consciência ou responsabilização pessoal a priori, é também um processo construído, conquistado na conjunção das condições materiais, da atividade do sujeito e da ressignificação de suas vivências. Por outro lado, se Moser (2009) aponta a existência de perfis de agricultores na relação com as inovações das práticas agrícolas sustentáveis, e a presença de responsabilização pessoal ambiental em produtores orgânicos, nossa pesquisa evidencia movimentos internos desses agricultores, apontando para a necessária incorporação do componente temporal nessa implicação. No tempo, dialogam determinantes "externos" e "internos", movendo os sujeitos em momentos mais ou menos aderentes ao SAF. Parece-nos que é o sucesso do SAF que pode consolidar melhor a alternativa criada e as subjetividades dela derivadas.

No que se refere à relação com a cidade, a pesquisa corrobora o que Ryan, Erickson e De Young (2003) e Moser (2009) descrevem acerca do papel da 
prática agroflorestal na criação de valores positivos dos agricultores. No estudo com os assentados, adiciona-se o fato de que o modelo do assentamento agroflorestal atua na mediação de conflitos com a cidade, ocorridos com a chegada na localidade, quando se destaca, mais do que o modelo do assentamento, o pertencimento dos sujeitos a um grupo carregado de imagens sociais negativas. As trocas bastante intensas, permitidas pela posição fronteiriça entre cidade e campo em área periurbana, dinamizamse também quando a produção agroflorestal começa a penetrar na cidade. A implantação e a vivência do SAF estruturam repertórios, discursos e práticas que os reposiciona no jogo de tensões e partilha com a cidade, inserindo-os como sujeitos empoderados em seus discursos, pela responsabilidade da preservação ambiental, pela oferta de produtos saudáveis e pelo sentimento de proteção dos recursos hídricos do município. Assim, tal como descrito por Brandemburg (2012) acerca da sociabilidade das relações campocidade no rural socioambiental, não apenas a cidade é o centro de atenção dos assentados, mas o assentamento agroflorestal, pela novidade que implanta, passa a atrair olhares curiosos da cidade, agora voltados para o conhecimento interessado naquele espaço e em seus sujeitos.

Os resultados abrem possibilidades para que investigações futuras explorem melhor a mediação das práticas agroecológicas como um possível elemento de coesão social - que, de acordo com Pol (2001) é imprescindível para que haja sustentabilidade - entre assentamentos em áreas periurbanas e seu entorno. Também a relação entre empoderamento dos sujeitos ao longo do tempo e o envolvimento com o SAF poderia ser pesquisada como uma possível resultante da apropriação paulatina que os assentados fazem daquele espaço, transformando-o em um lugar para eles.

Esses resultados têm também implicações para a elaboração de políticas públicas para as áreas rurais, preocupadas com o engajamento de sujeitos em práticas agrícolas voltadas para a sustentabilidade. Fomentar acompanhamento técnico em consonância com os projetos das localidades e especializados em princípios agroecológicos parece imprescindível para a criação de mediações bem sucedidas das práticas produtivas dos assentados. Mapear os mediadores e os pontos de tensão com o entorno e criar instrumentos de valoração positiva dos sujeitos e de seus projetos também se evidenciam como essenciais para o manejo das políticas que querem levar em conta a dimensão humana da sustentabilidade. Se considerarmos ainda a sustentabilidade como a "compatibilidade entre dinâmicas sociais, econômicas e culturais e recursos ambientais no presente e no futuro" (Uzzell, Pol e Badenas, 2002, p. 28), a ação nessa direção, no contexto brasileiro, significa fortalecer o novo rural sustentável comprometido também com a superação das profundas desigualdades sociais que se expressam na conformação do campo brasileiro. Isso implica decidir investir no empoderamento de projetos cuja esperança está depositada na produção da vida e no fortalecimento dos sujeitos que deles emergem.

\section{AGRADECIMENTOS}

Agradecimentos à Fundação de Amparo à Pesquisa do Estado de São Paulo.

\section{REFERÊNCIAS}

Alves, A. F. \& Guivant, J. S. (2010). Redes e Interconexões: desafios para a construção da agricultura sustentável. INTERthesis, Florianópolis, 7(1), 1-27. DOI 10.5007/1807-1384.2010 v $7 \mathrm{n} 1 \mathrm{p} 1$

Arato, H. D., Martins, S. V., \& Ferrari, S. H. S. (2003). Produção e decomposição de serapilheira em um sistema agroflorestal implantado para recuperação de área degradada em ViçosaMG. Revista Árvore, 27(5), 715-721. DOI 10.1590/S010067622003000500014

Beduschi Filho, L.C. (2012). Tendências e perspectivas dos programas de segurança alimentar e nutricional nos territórios rurais da América Latina: reflexões a partir da sistematização de projetos e políticas públicas. Faz Ciência (Francisco Beltrão), $15,11-34$

Brandemburg, A. (2010). Do rural tradicional ao rural socioambiental. Ambiente e Sociedade, São Paulo, 8(2), 417-428. DOI 10.1590/S1414-753X2010000200013

Carvalho, R., Goedert, W. J., \& Armando, M. S. (2004). Atributos físicos da qualidade de um solo sob sistema agroflorestal. Pesquisa Agropecuária Brasileira, Brasília, 39, 1153-1155. DOI 10.1590/S0100-204X2004001100015

Cruz-Souza, F. (Org.). (2011). Desarrollo rural y sostenibilidad: estrategias y experiencias en España y Brasil. Palencia: Pais Romanico.

Ferraro Júnior, L. A. \& Sorrentino, M. (2011). Imaginário político e colonialidade: desafios à avaliação qualitativa das políticas públicas de educação ambiental. Ciência \& Educação (Bauru), 17(2), 339-352. DOI 10.1590/S1516-73132011000200006.

Firmiano, F. D. (2008). A formação cultural dos jovens do MST: a experiência do assentamento Mário Lago, em Ribeirão Preto. Dissertação de Mestrado, Programa de Pós-Graduação em Sociologia da Faculdade de Ciências e Letras - Unesp, Araraquara.

Froehlich, J. M. \& Monteiro, R. C. (2004). Transformações semânticas recentes do termo "rural": uma leitura a partir da perspectiva urbana. Raízes - Revista de Ciências Sociais e Econômicas (Campina Grande), 21(2), 304-312.

Gaskell, G. (2013). Entrevistas individuais e grupais. In M. W. Bauer \& G. Gaskell (Orgs.). Pesquisa qualitativa com texto, imagem e som: um manual prático (11. ed.) (pp. 64-89). Petrópolis, RJ: Vozes. 
Jaccoud, M. \& Mayer. R. (2008). A observação direta e a pesquisa qualitativa. In J. Poupart, J. Deslauriers, L. Groulx, A. Laperrière, R. Mayer, \& A. Pires. A pesquisa qualitativa: enfoques epistemológicos e metodológicos (pp. 254-294). Petrópolis, RJ: Vozes.

Leite, J. F. \& Dimenstein, M. (2013). Psicologia e contextos rurais. Natal: EDUFRN.

Maldonado, T. (1971). La speranza progettuale: ambiente e società. Torino: Einaudi.

Moreira, R. J. (2000). Críticas ambientalistas à Revolução Verde. Estudos Sociedade e Agricultura, Rio de Janeiro, 15, 39-52.

Moser, G. (2009). Psychologie environnementale: les relations home-environnement. Paris: De Boeck.

Piraux, M., Silveira, L., Diniz, P., \& Duque, G. (2012). Transição agroecológica e inovação socioterritorial. Estudos Sociedade e Agricultura, Rio de Janeiro, 20(1), 5-29.

Pol, E. (2001). Ejes de tensión y nueva agenda para la Psicología Ambiental: una perspectiva europea. In E. Tassara (Org.). Problemas interdisciplinares para uma psicologia ambiental do urbano (pp. 51-67). São Paulo: EDUC; FAPESP.

Pol, E. (2009). Sostenibilidad, ciudad y medio ambiente. Dinâmicas urbanas y construcción de valores ambientales. In R. García Mira \& P. V. Marcote (Orgs.). Sostenibilidad, valores y cultura ambiental (pp. 183-205). Madrid: Pirámide.

Ryan, R., Erickson, D., \& De Young, R. (2003). Farmers' motivations for adopting conservation practices along riparian zones in a Midwestern agricultural watershed. Journal of Environmental Planning and Management, 46, 19-37.

Silva. A. P. S. (2003). (Des)continuidade no envolvimento com o crime: construção de identidade narrativa de ex-infratores. São Paulo: IBCCRIM.

Silva, P. G. (2011). A incorporação da agroecologia pelo MST: reflexões sobre o novo discurso e experiência prática. Dissertação de Mestrado, Programa de Pós-Graduação em História, Instituto de Ciências Humanas e Filosofia, Universidade Federal Fluminense.

Soromenho-Marques, V. (2005). A constelação ambiental: metamorfoses na nossa visão do mundo. In L. Soczka (Org.).
Contextos humanos e psicologia ambiental (pp. 11-38). Lisboa: Fundação Calouste Gulbenkian.

Steenbock, W., Silva, R. O., Froufe, L. C. M. \& Seoane, C. E. (2013). Agroflorestas e sistemas agroflorestais no espaço e no tempo. In W. Steenbock (Org.). Agrofloresta, ecologia e sociedade (pp. 39-60). Curitiba: Kairós.

Tassara, E. T. O. \& Rabinovich, E. P. (2003). Perspectivas da Psicologia Ambiental. Estudos de Psicologia, Natal, 8(2), 339-340. DOI org/10.1590/S1413-294X2003000200018

Tassara, E. T. O. (2007). Urbanidade e periurbanidade(s): Reflexões sobre dimensões psicossociais das dinâmicas históricas. Série Documenta, Rio de Janeiro, 17, 1-19.

Uzzell, D., Pol, E., \& Badenas, D. (2002). Place identification, social cohesion and environmental sustainability. Environment and Behavior, 34(1), 26-53. DOI 10.1177/0013916502034001003

Varela, L. B. \& Santana, A. C. (2009). Aspectos econômicos da produção e do risco nos sistemas agroflorestais e nos sistemas tradicionais de produção agrícola em Tomé-Açu, Pará - 2001 a 2003. Revista Árvore, 33(1), 151-160. DOI 10.1590/S010067622009000100016 .

Vygotski, L. S. (2006). Obras escogidas IV: Psicologia Infantil. Madrid: Visor y A. Machado Libros. (Original publicado em 1933).

\section{Autores:}

Ana Paula Soares da Silva - Doutor, Universidade de São Paulo, Faculdade de Filosofia, Ciências e Lettras de Ribeirão Preto - FFCLRP-USP.

Eda Terezinha de Oliveira Tassara - Livre Docente, Universidade de São Paulo, Instituto de Psicologia - IPUSP.

\section{Endereço para correspondência:}

Ana Paula Soares da Silva

Faculdade de Filosofia, Ciências e Letras de Ribeirão Preto

Departamento de Psicologia

Av. Bandeirantes, 3900 - Bairro Monte Alegre

CEP 14040-901 Ribeirão Preto, SP, Brasil

E-mail: apsoares.silva@usp.br

Recebido em: 19.05.2014

Aceito em: 11.08.2014 